\title{
COGNUTUVE AND NEUROLOGICAL COMPLICATIONS OF BACTERIAL MENINGITIS IN ADULT PATIENTS: A HOSPITAL BASED STUDY

\author{
By
}

EMAN M. EL-GINDY ${ }^{1}$, FATMA A. ALI-ELDIN ${ }^{1}$, IMAN BAYOUMY ${ }^{2}$, LAMIAA ABDEL-MONEIM ${ }^{3}$ and WESAM A. IBRAHIM ${ }^{4}$

Departments of Tropical Medicine ${ }^{1}$, Neurology ${ }^{2}$, Bacteriology and Immunology ${ }^{3}$ and, Internal Medicine ${ }^{4}$, Faculty of Medicine, Ain Shams University, Cairo 11566

\section{Abstract}

Bacterial meningitis is associated with disabling sequelae in a significant proportion of patients. It is associated with high mortality, risk of neuropsychological sequelae and risk of cognitive impairment the purpose of this study is to assess cognitive and neurological complications in adult patients with bacterial meningitis.

A total of 45 patients with bacterial meningitis and 16 patients with tuberculous meningitis were enrolled. They were subjected to full medical history taking and clinical examination, full neurological examination on admission and discharge. Mini mental state examination (MMSE) and Wechsler memory scale (WMS) were used to assess cognitive function.

The results showed that the ischemic brain insult (87.88\%) followed by cranial nerves affection $(32.42 \%)$ were the commonest neurological complication detected on discharge. Cognitive impairment was detected in 53.66\% of patients using MMSE.WMS showed that orientation, information and logical memory were the most common affected. Cognitive and neurological complications were not statistically related to age or etiology $(\mathrm{P}>0.05)$.

Longer duration until diagnosis (Beta $=-.18, \mathrm{p}<0.001)$, presence of intracranial complications (Beta $=-.12, p<0.005)$, need for mechanical ventilation (Beta $=-.79, p<0.001)$ and drug abuse (Beta $=-0.11, p<0.05)$ were significant predictors of worse outcome assessed by Glasgow outcome score.

Key words: bacterial meningitis; tuberculous meningitis; cognitive impairment; neurologic complications

\section{Introduction}

Acute infections of the nervous system are among the most important problems in medicine because early recognition, efficient decision-making, and rapid institution of therapy can be lifesaving (Barlam and Kasper, 2012). Bacterial meningitis was associated with disabling sequel in a sig-nificant proportion of patients (Edmond et al, 2010). It was associated with high mortality, risk of neuropsychological sequel (Ramakrishnan et al, 2009) and risk of cognitive impairment (Hoogman et al, 2007). Mortality and serious long-term sequel still occur in about $50 \%$ of patients with tuberculosis meningitis (Anderson et al, 2010). There is little information about the severity and distribution of the different types of sequel (Edmond et al, 2010). The problem is more significant in resource-poor countries (Franco-Paredes et $a l, 2008)$. The aim of this work is to assess cognitive and neurological complications in adult patients diagnosed with bacterial meningitis in a single fever hospital in Egypt.

Patients, Materials and Methods

This study was performed in accordance with ethical standards and with approval of the Ethical committee of Ain Shams University. Informed consents were obtained from patients or patients' $1^{\text {st }}$ degree relatives if consciousness was affected. The right to refuse participation was emphasized. There were no conflicts of interest.

A total of sixty one adult patients diagnosed as bacterial meningitis at a fever hospital in Cairo, Egypt during the period from June 2013 to January 2015 were selected. Patients' diagnosis was by correlation between clinical symptoms and signs suggesting meningitis and laboratory results including CSF analysis. Diagnosis of bacterial and tuberculosis meningitis was rested on microbiological basis. 
Exclusion criteria: Patients with CSF picture suggestive of bacterial or tuberculosis meningitis with negative direct stain or culture and patients with aseptic or fungal meningitis were excluded from the study. Patients less than 16 years old were excluded due to difficulty of assessment of cognitive impairment. The patients were assessed on admission to the hospital and on discharge. 20 patients died and thus were not evaluated on discharge.

All patients were subjected to full medical history taking and clinical examina-tion, full neurological examination for assessment of neurological complications on admission and discharge. Assessment of cognitive function on discharge was done using the mini mental state examination (MMSE) and Wechsler memory scale (WMS). MMSE comprises multiple questions that evaluate different cognitive functions. The questions should be asked in the order listed and one point was scored for each correct response within each question. Score 0-17 indicates severe cognitive impairment, 18-23 indicates mild cognitive impairment, $>23$ indicated no cognitive impairment (Kurlowicz and Wallace, 1999). The WMS includes a number of subtests that test different cognitive functions (Miller et al, 2012). Assessment of outcome of patients was done using the Glasgow outcome scale (GOS) (Weisfelt et al, 2006). Patients were classified into poor (GOS: 1-4) and good (GOS=5) outcome (Shimohata et al, 2010).

Complete blood picture, erythrocyte sedimentation rate (ESR), Random blood sugar, Liver function tests, renal function tests and electrolytes were done for all. A diagnostic lumbar puncture was done upon admission for all cases and the collected CSF was examined for: naked eye examination (aspect and pressure), cell count (total and differential leukocytic count), bacterial examination (Gram stain, modified Ziehl Neelsen stain, culture \& sensitivity) and biochemical examination (glucose and protein contents).
Bacteriological examination: Cerebrospinnal fluid (CSF) was collected aseptically into a dry sterile container and immediately examined. After the appearance was reported, the CSF sample was divided into 2 parts in sterile container:

1- Centrifuged part: for pus cell count $/ \mathrm{mm}^{3}$ and total chemical analysis for total protein and glucose concentration.

2- Centrifuged part: the deposit was used for microscopic examination of smears stained with Gram and Modified Zeihl Neelsen stains and inoculation on culture media. Cerebrospinal fluid was cultured as soon as possible after collection. Inoculation was done on Chocolate agar, blood agar and MacConkey's medium. When Gram positive diplococci were in the Gram smear, an optochin disc was added to the blood agar plate to assist in identification of Strepto-coccus pneumoniae. Both plates were incubated in a carbon dioxide enriched atmosphere at 35$37^{\circ} \mathrm{C}$ for up to 48 hours, checking for growth after an overnight incubation.

Chocolate agar and blood agar cultures were examined especially for colonies that could be: Neisseria meningitidis (growing on chocolate agar and blood agar, oxidase positive), Streptococcus pneumonia (sensitive to optochin), Haemophilus influenzae (grown on chocolate agar). Conventional methods were used to identify Gram negative bacteria (Cheesebrough, 2007).

Statistical analysis: Data were processed and analyzed using the statistical package for social sciences (SPSS V 15.2, Echosoft Corp, USA, 2006) program. Data were expressed as mean and standard deviation (SD) for quantitative measures, and both number and percentage for categorized data. The following tests were used: independent samples t-test, Chi-square test. Correlation coefficient test (r-test) was used for different variables against each other either directly or indirectly. Multiple regression analysis was used to examine the effects of multiple predictors or independent variables on a single outcome variable. 
Probability of error $\mathrm{P}<0.05$ was considered significant, and $\mathrm{P}<0.01$ was considered highly significant.

\section{Results}

Sixty one patients were enrolled. Demographic data of the studied patients were summarized (table 1). 10 (15.87\%) patients

Table 1: Demographic data of the studied patients.

\begin{tabular}{|l|l|l|l|}
\hline \multicolumn{2}{|l|}{ Parameters } & No. & Percent \\
\hline \multirow{3}{*}{ Sex } & Male & 42 & $68.85 \%$ \\
\cline { 2 - 4 } & Female & 19 & $31.15 \%$ \\
\hline \multirow{3}{*}{ Oge group } & $16-40$ years & 37 & $60.66 \%$ \\
\cline { 2 - 4 } & 41-60 years & 15 & $24.59 \%$ \\
\cline { 2 - 4 } & $\geq 61$ years & 9 & $14.75 \%$ \\
\hline \multirow{3}{*}{ Special habits } & Manual work & 25 & $40.98 \%$ \\
\cline { 2 - 4 } & Mental work & 11 & $18.03 \%$ \\
\cline { 2 - 4 } & Unoccupied & 25 & $40.98 \%$ \\
\cline { 2 - 4 } & Smoking & 24 & $39.34 \%$ \\
\hline
\end{tabular}

Forty-five patients were diagnosed as bacterial meningitis $(73.77 \%)$ and 16 were TB meningitis $(26.23 \%)$. The following organisms were detected by culture in bacterial meningitis (45 patients): $S$. pneumonia (18 patients, 40\%), N. meningitidis (9 patients, 20\%), H. influenza (10 patients, 22.22\%), Staphylococcus aureus (6 patients, 13.33\%), Escherichia coli (2 patients, 4.45\%). Dura- were diabetics and 14 patients $(22.22 \%)$ had past history of head trauma. $10(15.87 \%)$ patients had history of previous attack of meningitis, 5 had past history of head trauma and 1 patient had past history of nasal surgery.

Table 2: Main neurological signs detected in patients on admission and discharge.

\begin{tabular}{|l|c|c|c|c|}
\hline \multirow{2}{*}{ Variants } & \multicolumn{2}{|c|}{ Admission (No. 61) } & \multicolumn{2}{c|}{ Discharge (No. 41) } \\
\cline { 2 - 5 } & No. & Percent & No. & Percent \\
\hline Glasgow coma scale $<15$ & 60 & $98.36 \%$ & - & - \\
\hline Speech affection & 30 & $49.18 \%$ & 1 & $2.44 \%$ \\
\hline Cranial nerve affection & 24 & $39.34 \%$ & 8 & $19.51 \%$ \\
\hline Gait disorders & - & - & 13 & $31.7 \%$ \\
\hline Neck rigidity & 53 & $86.89 \%$ & 1 & $2.44 \%$ \\
\hline Stretch signs & 45 & $73.77 \%$ & - & - \\
\hline Motor disorders & 33 & $54.1 \%$ & 8 & $19.51 \%$ \\
\hline Co-ordination disorders & 1 & $1.64 \%$ & 4 & $9.76 \%$ \\
\hline Reflex disorders & 34 & $55.74 \%$ & 7 & $17.07 \%$ \\
\hline Sensory disorders & - & - & 2 & $4.88 \%$ \\
\hline Incontinence & 58 & $95.08 \%$ & 4 & $9.76 \%$ \\
\hline
\end{tabular}

Discharged patients were $41 ; 20(32.79 \%)$ patients died (15 patients with bacterial meningitis and 5 patients with tuberculosis meningitis). The ischemic brain insult was the commonest representing $33 \%$ of patients with bacterial meningitis and $54.55 \%$ of pa- tion from presentation of symptoms until diagnosis ranged from 1 to 76 days with a mean of $9.65 \pm 14.24$ days and median 5. Duration of hospital stay ranged from 5 to 31 days with a mean of $12.67 \pm 5.47$ days.

Symptoms of patients on admission were principally fever $(100 \%)$, headache $(95.2 \%)$, disturbed conscious level (DCL) $(95.2 \%)$ and vomiting (79.4\%). tients with tuberculosis meningitis. There were no statistically significant relationship between neurological complications and diagnosis $(\mathrm{p}>0.05)$. 
Table 3: Neurological complications detected in patients on discharge.

\begin{tabular}{|c|c|c|c|c|c|c|}
\hline \multirow{2}{*}{ Variants } & \multicolumn{2}{|c|}{ Bacterial $(\mathrm{N}=30)$} & \multicolumn{2}{|c|}{$\mathrm{TB}(\mathrm{N}=11)$} & \multirow{2}{*}{$\mathrm{R}$} & \multirow{2}{*}{$\mathrm{P}$} \\
\hline & No. & $\%$ & No. & $\%$ & & \\
\hline Cranial nervesaffection & 7 & 23.33 & 1 & 9.09 & -0.15 & $>0.05$ \\
\hline Ischemic brain insult & 10 & 33.33 & 6 & 54.55 & -0.12 & $>0.05$ \\
\hline Seizures & 1 & 3.33 & - & - & - & - \\
\hline Speech disorders & 1 & 3.33 & - & - & - & - \\
\hline Hydrocephalus & - & - & 1 & 9.09 & - & - \\
\hline
\end{tabular}

Cognitive impairment was in 22/ 41 patients $(53.66 \%)$ using MMSE, without relationship between etiology of meningitis and cognitive impairment. The cognitive imp-

Table 4: Cognitive complications detected in patients on discharge (41 cases).

\begin{tabular}{|c|c|c|c|c|c|c|c|}
\hline \multirow{2}{*}{\multicolumn{2}{|c|}{ Variants }} & \multicolumn{2}{|c|}{$\operatorname{Bacterial}(\mathrm{N}=30)$} & \multicolumn{2}{|c|}{$\mathrm{TB}(\mathrm{N}=11)$} & \multirow{2}{*}{$\mathrm{R}$} & \multirow{2}{*}{$\mathrm{P}$} \\
\hline & & No & $\%$ & No & $\%$ & & \\
\hline \multirow{2}{*}{$\sum_{\Sigma}^{\pi}$} & Mild impairment (18-23) & 11 & 36.67 & 4 & 36.36 & \multirow{2}{*}{0.10} & \multirow{2}{*}{$>0.05$} \\
\hline & Severe impairment $(0-17)$ & 4 & 13.33 & 3 & 27.27 & & \\
\hline \multirow{6}{*}{$\sum_{3}^{\infty}$} & Impaired Information & 12 & 40 & 6 & 54.54 & 0.11 & $>0.05$ \\
\hline & Impaired Orientation & 14 & 46.67 & 5 & 45.45 & -0.06 & \\
\hline & Impaired Mental Control & 7 & 23.33 & 5 & 45.45 & -0.23 & \\
\hline & Impaired Logical Memory & 11 & 36.67 & 4 & 36.36 & -0.02 & \\
\hline & Impaired Digits total & 10 & 33.33 & 4 & 36.36 & 0.05 & \\
\hline & Impaired Associate Learning & 9 & 30 & 2 & 18.18 & -0.17 & \\
\hline
\end{tabular}

Using GOS, 20 patients died (GOS1) and 20 had a complete recovery (GOS 5); 16 $(35.56 \%)$ patient with bacterial meningitis and $4(25 \%)$ with TB meningitis. On the other hand, 18 patients had a GOS 3 (severe disability); 13 (28.89\%) bacterial meningitis and $5(31.25 \%)$ TB meningitis patients, 3 patients had a GOS 4 (moderate disability),

airment and neurological complications were not statistically related to age ( $\mathrm{r} 0.03$, $\mathrm{P}>0.05 \& \mathrm{r}-0.13, \mathrm{P}>0.05$ respectively).

$1(2.22 \%)$ bacterial meningitis and 2 (12.5) TB meningitis patients. None of the patients was in vegetative state (GOS 2). Higher total leucocytic count and serum creatinine level was shown to be associated with poor outcome assessed by GOS and higher hemoglobin concentration was associated with better outcome.

Table 5: Correlation between laboratory findings and outcome.

\begin{tabular}{|l|c|c|c|c|c|}
\hline Variants & $\begin{array}{c}\text { Good outcome } \\
\text { (GOS:5) } 20 \text { cases }\end{array}$ & $\begin{array}{c}\text { Poor outcome } \\
\text { (GOS:1-4) 41 cases }\end{array}$ & $\mathrm{T}$ & $\mathrm{P}$ & Sig. \\
\hline Hemoglobin $(\mathrm{g} / \mathrm{dl})$ & $12.5 \pm 2.14$ & $11.7 \pm 2.28$ & 1.92 & $<0.05$ & $\mathrm{~S}$ \\
\hline Total leukocytes $\left(\mathrm{x} 10^{3} / \mathrm{ul}\right)$ & $11.5 \pm 4.59$ & $16.3 \pm 8.22$ & -2.87 & $<0.01$ & $\mathrm{HS}$ \\
\hline Platelets $\left(\mathrm{x} 10^{3} / \mathrm{ul}\right)$ & $263 \pm 94.93$ & $248 \pm 87.08$ & .65 & $>0.05$ & $\mathrm{NS}$ \\
\hline ESR & $37 \pm 23.41$ & $42 \pm 29.00$ & -.71 & $>0.05$ & $\mathrm{NS}$ \\
\hline Random blood sugar $(\mathrm{mg} / \mathrm{dl})$ & $136 \pm 112.55$ & $157 \pm 79.73$ & -.67 & $>0.05$ & NS \\
\hline ALT $(\mathrm{IU} / \mathrm{ml})$ & $36 \pm 30.80$ & $42 \pm 42.16$ & .53 & $>0.05$ & NS \\
\hline S. Creatinine $(\mathrm{mg} / \mathrm{dl})$ & $0.86 \pm 0.36$ & $1.75 \pm 2.42$ & -1.41 & $<0.05$ & $\mathrm{~S}$ \\
\hline
\end{tabular}

An independent sample $t$ test firstly diagnosed as bacterial meningitis versus patients with recurrent meningitis (45 cases) as regards GOS, duration till diagnosis and duration of hospital stay. Patients with recurrent meningitis had significantly better outcome $($ mean=4.2) compared to patients firstly diagnosed as bacterial meningitis (mean $=3$ )
$(\mathrm{P}<0.05)$. However, there was no significant relationship between duration till diagnosis, duration of hospital stay and recurrence $(\mathrm{p}>0.05)$. Multiple regression analysis was conducted to examine risk factors influence on the outcome (measured on GOS from 1$5)$. Longer duration until diagnosis $($ Beta $=-$. $18, \mathrm{p}<0.001$ ), presence ofintracranial com- 
plications (Beta $=-.12, \mathrm{p}<0.005)$, need for mechanical ventilation $($ Beta $=-.79, \mathrm{p}$ $<0.001)$ and drug abuse (Beta $=-0.11, \mathrm{p}<$ $0.05)$ were significant predictors of worse outcome.

Systemic complications detected in the patients were hospital acquired infections (63.93\%) including respiratory tract infection (25 patients, $40.98 \%$ ) and urinary tract infection (14 patients, 22.95\%), Hyponatremia (25 patients, $40.98 \%$ ), sepsis (21 patients, $34.43 \%) \&$ organ failure $(27.87 \%)$ including renal (6 patients, 9.84\%) and respiratory failure (11 patients, $18.03 \%$ ).

\section{Discussion}

Survivors of bacterial meningitis are at risk from long-term disabling sequel and impaired quality of life. There was little information about the severity and distribution of different types of sequelae. Data were especially poor from low-income countries, where the risks of infection were highest and care was least accessible (Edmond et al, 2010).

In the present study, patients were 42 males $(68.85 \%)$ and 19 females $(31.15 \%)$ with male predominance, which was comparable to Zaky et al. (2014) who reported that meningitis male patients represented $(53 \%)$ of their patients. Mace (2008) reported that male gender is a risk factor for meningitis. The patients' ages ranged from 16 to 77 years, but younger age group (16-40 years) was the most representing group $(60.66 \%)$. This was in line with the other reported that $67.5 \%$ of the adult meningitis patients were between 20-40 years (Zaky et al, 2014). But, van de Beek et al. (2004) in Netherlands reported that the meningitis age distribution of shifted to older age groups, which could be due to effective vaccination programs there.

The following organisms were detected by culture in 45 patients: S. pneumoniae (18 patients, 40\%), N. meningitides (9 patients, $20 \%$ ), H. influenza (10 patients, $22.22 \%$ ), $S$. aureus (6 patients, $13.33 \%$ ), E. coli (2 patients, $4.45 \%$ ). This was comparable to Zaky et al. (2014) who reported that in adult meningitis patients, the causative organisms were $S$. pneumoniae $(37.5 \%), H$. influnzae (25\%), and N. meningitides (17.5\%).

In the present study, neurological complications detected on discharge in patients with bacterial meningitis were mainly ischemic brain insult $(33.33 \%)$ and cranial nerve affection $(23.33 \%)$. van de Beek et al. (2004) reported that cranial nerve palsies affected $16 \%$, hearing impairment $14 \%$, hemiparesis $4 \%$ and aphasia $2 \%$ of bacterial meningitis patients. Zaky et al. (2014) reported cranial nerve palsies in $5 \%$ of patients and deafness in $10 \%$ of the patients. Pfister et al. (1993) reported that the major intracranial complications included cerebrovascular involvement $(15.1 \%)$, brain edema (14.0\%), hydrocephalus (11.6\%), and intracerebral hemorrhage $(2.3 \%)$.

In the present study, TB meningitis patients suffered ischemic brain insult in $54.55 \%$, cranial nerve affection and hydrocephalus in $9.09 \%$ each. Anderson et al. (2010) reported that neurological complications of patients with TB meningitis were mainly hydrocephalus $42 \%$, stroke $33 \%$, cranial nerve palsies $29 \%$ and epileptic seizures 28\%. Kalita et al. (2007) reported that neurological sequel of TB meningitis were mainly motor deficit in $40 \%$, optic atrophy in $37 \%$ and other cranial nerve palsy in $23 \%$ of patients.

In the present study, the MMSE revealed that $50 \%$ of tested bacterial meningitis patients and $63.64 \%$ of tested TB meningitis patients had cognitive impairment. Wechsler Memory Scale (WMS), revealed that the impaired different memory functions in tested patients were information (43.9\%), orientation (46.34\%), mental control (29.27\%), logical memory (36.59\%), digits total (34.15\%) and associate learning (26.83\%) with no significant difference between patients with bacterial meningitis and those with tuberculosis meningitis.

After bacterial meningitis, patients were at high risk of cognitive impairment (Hoogman 
et al, 2007). Kalita et al. (2007) reported that cognitive impairment affected 55\% of patients with TB meningitis. Anderson et al. (2010) reported that the commonest complications in the long-term survivors of TB meningitis patients were cognitive impairment $(12 \%)$.

Hoogman et al. (2007) reported that approximately one third of adult survivors of bacterial meningitis experience subtle cognitive impairment, which consists mainly of slight mental slowness. However, van de Beek et al. (2004) reported much less percentage of cognitive disorder $(27 \%)$ in patients with bacterial meningitis, difference could be attributed to the selection of patients with good outcome (GOS=5).

In the present study, the overall mortality rate was $(32.79 \%)$. Mortality rate for patient with bacterial meningitis was $33.33 \%$ and was $31.25 \%$ in patients with TB meningitis. Girgis et al. (1993) reported that the mortality rate was almost $55 \%$ for TB meningitis patients and approximately $40 \%$ for both pneumococcal and Haemophilus patients, it was $8.5 \%$ in patients with meningococcal disease. In a more recent study in Egypt mortality rate was $27.5 \%$ in adult patients with bacterial meningitis (Zaky et al, 2014). A study in Uganda reported that the inhospital mortality for patients with bacterial meningitis was $58.8 \%$ (10 of 17 ) and $28.1 \%$ (9 of 32) for TB meningitis (Majwala et al, 2013). Lucas et al. (2013) in Amsterdam reported $179 / 1001$ mortality of patients with bacterial meningitis $(17.88 \%)$.

In the present study, $64.44 \%$ of bacterial meningitis patients had unfavorable outcome (GOS 1-4) (33.33\% died and 31.11\% cured with sequel) and $75 \%$ of TB meningitis patients had unfavorable outcome (GOS 1-4) (31.25\% died and $43.75 \%$ cured with sequelae). In a nationwide study in Netherland, Lucas et al. (2013) reported that 21\% of their patients with bacterial meningitis cured with sequel (GOS 2-4). Unfavorable outcome (GOS 1-4) was reported in $40 \%$ of patients with low Glasgow coma scale score on admission (Lucas et al, 2014). Also, van de Beek et al. (2004) reported that the outcome was unfavorable in $34 \%$ of episodes of bacterial meningitis patients. Meanwhile, Kastenbauer and Pfister (2003) agreed that only $48.3 \%$ of pneumococcal meningitis patients had a favorable outcome at discharge. Girgis et al. (1998) reported that of 857 TB meningitis patients, (57\%) died, (30\%) recovered completely, and (13\%) recovered with sequelae. The lower mortality rates in the present TB patients compared to Girgis et al. (1998) might be attributed to the presence of more patients who cured with complications.

An inspection of individual predictors revealed that duration until diagnosis (Beta $=$ $.18, \mathrm{p}<.001)$, Intracranial complications $($ Beta $=-.12, p<.005)$, need for mechanical ventilation (Beta $=-.79, \mathrm{p}<.001)$ and drug abuse are significant predictors of worse outcome. Radetsky (1992) reported that for patients with a history of clinically overt meningitis, an inappropriate delayed in commencing therapy incrementally increased the risk of permanent injury. KøsterRasmussen et al. (2008) reported that the delay in antibiotic therapy correlated independently to unfavorable outcome. Girgis et al. (1998) reported that the mortality and neurologic sequelae were directly related to the stage of disease and duration of symptoms prior to admission. Also, Kastenbauer and Pfister (2003) reported that, intracranial and systemic complications are associated with unfavorable outcome. Male sex and cranial nerve palsy at discharge were risk factors for cognitive impairment (Hoogman et al, 2007).

In the present study recurrent bacterial meningitis was identified in ten (15.8\%), their etiology was principally due to local causes $(60 \%)$ while both decreased immunity and chronic illness were present in $10 \%$ each, the rest of patients had unidentifiable cause. This agreed with Durand et al. (1993) who reported that frequency of recurrent meningitis cases was $9 \%$ among 435 pa- 
tients with bacterial meningitis. However, van de Beek et al. (2004) reported that number of recurrent meningitis cases was $5 \%$ of 696 bacterial meningitis cases. This result also agreed with Tebruegge and Curtis (2008) which included a total of 363 cases of recurrent meningitis, of these cases, 59\% were related to anatomical problems, 36\% were related to immunodeficiency, and 5\% were related to para-meningeal infections.

In the present study, the results revealed significant relationship $(\mathrm{P}<.05)$ between outcome and recurrence, patients with recurrent meningitis had better outcome (mean=4.2) compared to patients firstly diagnosed as bacterial meningitis (mean=3). This agreed with Durand et al. (1993) who reported $25 \%$ mortality rate for single episode of bacterial meningitis but for recurrent episodes of bacterial meningitis was $6 \%$. This might be explained that patients with recurrent meningitis and their families usually know the presenting symptoms and present early to specialized medical service, which permits early management of their illness.

\section{Conclusion}

The cognitive and neurological complications in patients with bacterial and tuberculosis meningitis are serious problems in Egypt. More efforts should be achieved to detect and manage cognitive and neurological complications in meningitis patients. Significant predictors of poor outcome are longer duration until diagnosis, intracranial complications, and need for mechanical ventilation and drug abuse. Specialized outpatient visits might be provided for follow up of such patients. Recurrent meningitis is a significant entity of bacterial meningitis. Vanishing predisposing factors and proper vaccination should be directed to these patients.

\section{References}

Anderson, NE, Somaratne, J, Mason, DF, Holland, D, Thomas, MG, 2010: Neurological and systemic complications of tuberculous meningitis and its treatment at Auckland City
Hospital, New Zealand. J. Clin. Neurosci. 17, 9: 1114-8.

Barlam, T, Kasper, D, 2012: Meningitis, Encephalitis, Brain Abscess, and Empyema. Harrison's Principles of Internal Medicine, Longo D., Fauci A., Kasper D. et al. (Editors), $18^{\text {th }}$. edition, Maryland, USA.

Cheesebrough, M, 2007: District Laboratory Practice in Tropical Countries. $2^{\text {nd }}$ ed. New Yourk: Cambridge University Press.

Durand, ML, Calderwood, SB, Weber, DJ, Miller, SI, Southwick, FS, et al, 1993: Acute bacterial meningitis in adults. A review of 493 episodes. N. Engl. J. Med. 7: 328, 1:21-8.

Edmond, K, Clark, A, Korczak, VS, Sanderson, C, Griffiths, UK, et al, 2010: Global and regional risk of disabling sequelae from bacterial meningitis: a systematic review and meta-analysis. Lancet Infect. Dis. 10:317-28.

Franco-Paredes, C, Lammoglia, L, Herna'ndez, I, Santos-Preciado, JI, 2008: Epidemiology and outcomes of bacterial meningitis in Mexican children: 10-year experience (19932003). Int. J. Infect. Dis. 12:380-6.

Girgis, NI, Sippel, JE, Kilpatrick, ME, Sanborn, WR, Mikhail, IA, et al, 1993: Meningitis and encephalitis at the Abbassia Fever Hospital, Cairo, Egypt, from 1966 to 1989. Am. J. Trop. Med. Hyg. 48, 1:97-107.

Girgis, NI, Sultan, Y, Farid, Z, 1998: Tuberculous meningitis, Abbassia Fever HospitalNAMRU-3, Cairo, Egypt, from 1976 to 1996. Am. J. Trop. Med. Hyg. 58, 1:28-34.

Hoogman, M, van de Beek, D, Weisfelt, M, de Gans, J, Schmand, B et al, 2007: Cognitive outcome in adults after bacterial meningitis. J. Neurol. Neurosurg. Psychiat. 78, 10:1092-6.

Kalita, J, Misra, UK, Ranjan, P, 2007: Predictors of long-term neurological sequelae of tuberculous meningitis: a multivariate analysis. Eur. J. Neurol. 1:33-7.

Kastenbauer, S, Pfister, HW, 2003: Pneumococcal meningitis in adults: spectrum of complications and prognostic factors in a series of 87 cases. Brain 126, Pt 5:1015-25.

Køster-Rasmussen, R , Korshin, A, Meyer, C N, 2008: Antibiotic treatment delay and outcome in acute bacterial meningitis. J. Infect. 57, $6: 449-54$.

Kurlowicz, L, Wallace, M, 1999: The minimental state examination. J. Gerontol. Nurs. 25, 5: $8-9$. 
Lucas, MJ, Brouwer, MC, van der Ende, A, van de Beek, D, 2013: Endocarditis in adults with bacterial meningitis. Circulation 127: 205662.

Lucas, MJ, Brouwer, MC, van der Ende, A, van de Beek, D, 2014: Outcome in patients with bacterial meningitis presenting with a minimal GlasgowComa Scale score. Neurol. Neuroimmunol. Neuroinflamm, doi 10.1212/NXI.0000000000000009.

Mace, SE, 2008: Acute bacterial meningitis. Emerg. Med. Clin. North Am. 26, 2:281-317.

Majwala, A, Burke, R, Patterson, W, Pinkerton, R, Muzoora, C, et al, 2013: Handheld point-of-care cerebrospinal fluid lactate testing predicts bacterial meningitis in Uganda. Am. J. Trop. Med. Hyg. 88, 1:127-31

Miller, JB, Axelrod, BN, Rapport, LJ, Millis, SR, Vandyke, S, et al, 2012: Parsimonious prediction of Wechsler Memory Scale, $4^{\text {th }}$ edition scores:immediate and delayed memory indexes. J. Clin. Exp. Neuropsychol. 34, 5:53142.

Pfister, HW, Feiden, W, Einhäupl, KM, 1993: Spectrum of complications during bacterial meningitis in adults. Results of a prospective clinical study. Arch. Neurol. 50, 6:575-81.

Radetsky, M, 1992: Duration of symptoms and outcome in bacterial meningitis: an analysis of causation and the implications of a delay in diagnosis. Pediatr. Infect. Dis. J. 9:694-8.
Ramakrishnan, M, Ulland, AJ, Steinhardt, LC, Moïsi, JC, Were, F, et al, 2009: Sequelae due to bacterial meningitis among African children: a systematic literature review. BMC Med. 7:47-54.

Shimohata, T, Yanagawa, K, Tanaka, K, Nishizawa, M, 2010: Clinical features of poorprognosis patients with adult bacterial meningitis. Rinsho Shinkeigaku 50, 3:137-40.

Tebruegge, M, Curtis, M, 2008: Epidemiology, etiology, pathogenesis, and diagnosis of recurrent bacterial meningitis. Clin. Microbiol. Rev. 21, 3:519-37.

van de Beek, D, de Gans, J, Spanjaard, L, Weisfelt, M, Reitsma, JB, et al, 2004: Clinical features and prognostic factors in adults with bacterial meningitis. N. Engl. J. Med. 351, 18:1849-59.

Weisfelt, M, van de Beek, D, Hoogman, M, Hardeman, C, de Gans, J, Schmand, B, 2006: Cognitive outcome in adults with moderate disability after pneumococcal meningitis. J. Infect. 52, 6:433-9.

Zaky, S, Abdel Baki, A, Farouk, S, Sabry, S, Deraz, AS, et al, 2014: Presentation, prognostic factors and outcome of acute septic meningitis in an egyptian fever hospital. Ind. J. Sci. Res. and Tech. 2, 5:112-8. 